\title{
STRENGTH, DURABILITY AND MICROSTRUCTURE INVESTIGATIONS OF CONCRETE CONTAINING EMPTY PALM OIL FRUIT BUNCH ASH (EPO-FBA)
}

\author{
Christopher Ajiboye Fapohunda ${ }^{1}$, Ayotunde Olumide Babatola ${ }^{1}$ and Olawale \\ Blessing Oluwasegunota ${ }^{1}$
}

\author{
Federal University, Oye-Ekiti, Faculty of Engineering, Department of Civil Engineering, \\ Nigeria; christopher.fapohunda@fuoye.edu.ng
}

\begin{abstract}
Understanding of the internal arrangement of the constituents of structural concrete, at the microscopic level, and its strength behavior, as well as its ability to result in durable concrete, are necessary in order to enhance its innovative and sustainable application. This paper presents the results of investigation conducted to ascertain the strength characteristics, microstructure configuration and durability traits of concrete with its ordinary Portland cement (OPC) fraction replaced partially with empty palm oil fruit bunch ash (EPO-FBA). The compressive strength properties were assessed with $150 \times 150 \times 150$ cube specimens while $100 \times 100 \times 100$ cube specimens were used to assess the durability properties. An insight into the morphology and the microstructure of samples with EPO-FBA was obtained through Scanning Electron Microscopy (SEM). The results showed that EPO-FBA is a good supplementary cementing material up to $10 \%$ replacement level, however, the samples with EPO-FBA showed a significantly improved compressive strengths development and good durability characteristics at latter ages, at the replacement level beyond $10 \%$.
\end{abstract}

\section{KEYWORDS}

Compressive strength, Microstructure, Sorptivity, Water absorption

\section{INTRODUCTION}

Sustainable design and practices in structural concrete require that: (i) usage of materials be optimized, (ii) unsuitable materials be made fit, (iii) new materials be developed to minimize and conserve the consumption of non-renewable materials used in the production of structural concrete, and (iv) materials be used innovatively. Thus, understanding of the internal arrangement of the constituents of structural concrete, at the microscopic level, and its strength behavior, as well as its ability to result in durable concrete, are necessary in order to enhance its innovative and sustainable application. The relative lack of success in developing microstructure/property relationships for concrete is due to the apparent lack of good microstructural characterization. It is well-known that concrete has a heterogeneous and complex microstructure, which has made it difficult to construct realistic models of its microstructure [1]. Knowledge of its microstructure would have enabled the behavior of the material to be reliably predicted [2]. The heterogeneity of concrete, according to [1], can be considered on several levels, with the simplest level, consisting of aggregate particles, distributed in a matrix of cement paste. On a more detailed level, says [1] the paste itself is a mixture of unreacted cement, hydration products, pores, and water and at a still finer level these phases themselves have complex microstructures. While it is known that the hydration products control the strength and mechanical properties of concrete, the pores (sizes, distribution, continuity/discontinuity), on the other hand governs the durability characteristics of concrete. Thus, 


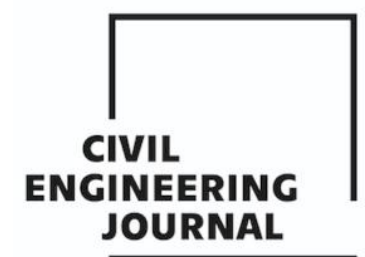

Article no. 38

THE CIVIL ENGINEERING JOURNAL 2-2021

understanding the microstructure and properties of the individual components of concrete and their relationship to one another can serve as a means of re-constructing and re-configuring its properties for innovative application. This is because microstructure of a material determines many of its physical and mechanical properties [3]; in this case, the strength and durability characteristics of structural concrete. This is particularly important for materials sourced from agricultural wastes that are being discovered as potential structural material for enhancement of sustainability in structural concrete in developing countries. For many of these materials, a complete structural response is yet to be captured. For example, there is paucity of literature on the microstructure of concrete with the ordinary Portland cement portion partly replaced with the empty palm oil fruit bunch ash (EPO-FBA). The earlier work by [4] on the possible use of EPO-FBA as partial replacement of ordinary Portland cement (OPC) in concrete covers little area. For example, only the latter ages (60, 75, and 90 days) were considered. According to [5], without 28 days' strength, the results seemed to lack any constructional and structural value. This is because the 28 days' strength is what is used in the design of structural concrete in codes and standards, and many other properties of concrete for construction purposes are linked to the 28-day strength. However, their work yielded a useful insight into the levels of replacement of OPC with EPO-FBA in concrete that will not affect the compressive strength of the concrete. The value was $15 \%$ by weight of the OPC. Subsequent work by [6] tried to address this shortcoming. But their work, though with expanded scope, did not however extend to microstructure and durability investigations of concrete with EPO-FBA. Also, the work of (7) dealing with the use of the ashes of oil palm empty fruit bunch was limited to mortar only. In all these investigations, durability and microstructural studies were conspicuously absent. Thus, the aim of this investigation is to assess the compressive strength, microstructure and durability characteristics of concrete with EPO-FBA as partial substitute of its OPC fractions. Specific objectives to be achieved for the concrete samples with EPO-FBA as partial replacement of cement are (i) determination of compressive strength development, (ii) assessment of durability properties through water absorption and sorptivity, and (iii) morphological investigations using scanning electron microscopy (SEM).

\section{MATERIALS AND METHODS}

\section{Materials}

Investigations in this work were carried out by using the following materials.

\section{The Binder.}

Ordinary Portland Cement (OPC), produced to satisfy the requirements of $[8,9]$, and classified as grade 42.5.was used as the binder for this work.

\section{Fine Aggregates}

A sand deposit at Ootunja, a settlement near Ikole Ekiti, Nigeria, served as the source of the fine aggregate used for this work. In order to ensure the fitness of the sand for use in structural concrete as per [10], the sand was dried and sieved through sieve $2.36 \mathrm{~mm}$. All forms of debris and other deleterious materials were also removed.

\section{Coarse Aggregates}

An active quarry, located in Ikole town in Ekiti State, Nigeria, serves as the source of the coarse aggregates used for this work. The size of the aggregates ranged from $4.75 \mathrm{~mm}$ to $20 \mathrm{~mm}$ as per the recommendation of [11] in relation to aggregate for structural concrete.

\section{Empty Palm Oil Fruit Bunch Ash (EPO-FBA).}

The empty palm oil fruit bunch ash (EPO-FBA) used to partially replace the OPC was obtained from empty palm oil fruit bunches, which were collected from palm oil industries in IkoleEkiti, Nigeria. Thebunches were sun-dried (Figure 1) and then pulverized.

In order to obtain the ash, the pulverized empty palm oil fruit bunches were burnt through open field burning as described by [12]. The ash samples passing through $45 \mu \mathrm{m}$ test sieve were collected, 


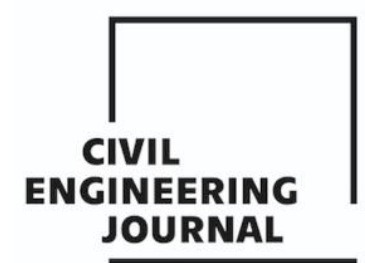

Article no. 38

THE CIVIL ENGINEERING JOURNAL 2-2021

bagged and stored in a cool place.

Water

For the execution of this research work, potable water that satisfied the requirement of [13] was used.

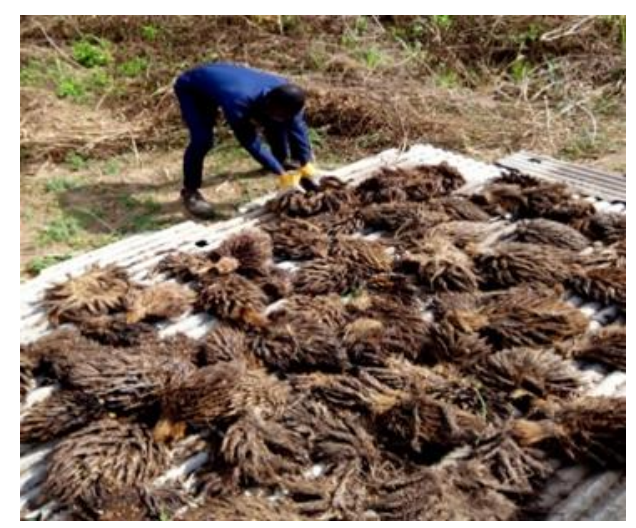

Fig. 1 - Drying of Empty Palm Oil Fruit Bunches

\section{Mix Proportion, Design and Concreting}

In order to model Nigerian field situations as much as possible, a mix proportion of 1:2:4 and water/cement ratio were chosen. These values were chosen to align with practice in Nigeria. The cement fraction in the mix was partially replaced with EPO-FBA up to $15 \%$ at interval of $5 \%$ by weight. Observations by [4] had showed that, beyond $15 \%$ replacement values, the strength development was very low. The mix proportion is presented in Table 1.

Tab. 1: The Mix Proportion used for the Investigation

\begin{tabular}{|c|c|c|c|c|c|c|}
\hline \multirow{2}{*}{$\begin{array}{c}\text { \% EPO-FBA } \\
\text { in the Mix }\end{array}$} & $\begin{array}{c}\text { Mix } \\
\text { Designation }\end{array}$ & \multicolumn{2}{|c|}{ Binder $\left(\mathrm{kg} / \mathrm{m}^{3}\right)$} & Fine Aggregate & $\begin{array}{c}\text { Coarse Aggregate } \\
\left(\mathrm{kg} / \mathrm{m}^{3}\right)\end{array}$ & $\begin{array}{c}\text { Water } \\
\left(\mathrm{kg} / \mathrm{m}^{3}\right)\end{array}$ \\
\hline 0 & $M_{0}$ & 343 & 0.00 & 686 & 1372 & 172 \\
\hline 5 & $M_{5}$ & 325.85 & 17.15 & 686 & 1372 & 172 \\
\hline 10 & $M_{10}$ & 308.70 & 34.30 & 686 & 1372 & 172 \\
\hline 15 & $M_{15}$ & 291.55 & 51.45 & 686 & 1372 & 172 \\
\hline
\end{tabular}

Concreting was carried out by measuring out the concrete ingredients by weight, thoroughly mixed and cast into moulds. Two types of moulds were used during the investigation. The $150 \times 150$ x $150 \mathrm{~mm}$ cubes were used for compressive test specimens and $100 \times 100 \times 100 \mathrm{~mm}$ cube moulds were used for durability tests specimens. The cast concrete specimens were then properly compacted by tamping. The specimens were left in the moulds for 24 hours, after which they were de-moulded, and then placed in curing tank for curing process. All the concrete specimens were moist cured in a curing tank, until the day of testing. The testing days were 7, 14, 28, 60 and 90 days for compressive test specimens. The durability test specimens were tested at 28 and 90 days of curing. The 28-day samples were used for microscopic investigations. The specimens without EPOFBA served as the control. A total of 60 numbers $150 \times 150 \times 150 \mathrm{~mm}$ cube specimens and 48 numbers of $100 \times 100 \times 100 \mathrm{~mm}$ cube specimens were cast. 


\section{Experimental procedures}

\section{Determination of Physical and Chemical Properties of the Materials}

Preliminary investigation was carried out to characterized the materials used by determining some of their properties. Physical properties like: specific gravity, moisture content, water absorption, dry density, bulk density and sieve analysis, were carried out on the aggregates. Chemical and physical tests were also performed on samples of EPO-FBA to determine its oxide composition and some physical properties like fineness (dry-sieving on $45 \mu \mathrm{m}$ ) and specific gravity.

\section{The Compressive Strength Test}

The compressive strength of concrete specimens containing EPO-FBA were assessed using $150 \times 150 \times 150 \mathrm{~mm}$ cube specimens. This was carried out in accordance to the provisions of [14]. A $2000 \mathrm{KN}$ WAW-2000B computerized electrohydraulic servo universal testing machine with accuracy of $\pm 1 \%$ of test force, was used to determine the compressive strength. Three specimens were tested at the testing date, and the average used to evaluate the mean strength.

\section{Water Absorption Test}

According to [15], absorption is a measure of the volume of pore space in concrete. A method suggested by $[16,17]$ is used to assess this property. To conduct this experiment, $100 \mathrm{~mm} \times 100 \mathrm{~mm}$ $x 100 \mathrm{~mm}$ concrete cubes specimens were cast and were moist-cured in a curing tank for 28 and 90 days. At each of the testing day, the cube specimens were taken out of the curing tank and ovendried at temperature of $105^{\circ} \mathrm{C}$ until a constant weight was reached. The specimens were then sealed, and then allowed to cool in a container for three days. Silicone sealant was then used to coat the sides of the concrete samples so that flow is constrained to flow in one direction. Then the samples were positioned in a vertical position and partially immersed in water to a depth of $5 \mathrm{~mm}$ at one end. The rest of the portions were kept exposed to the laboratory air as shown in Figure 2 as adapted from [16].

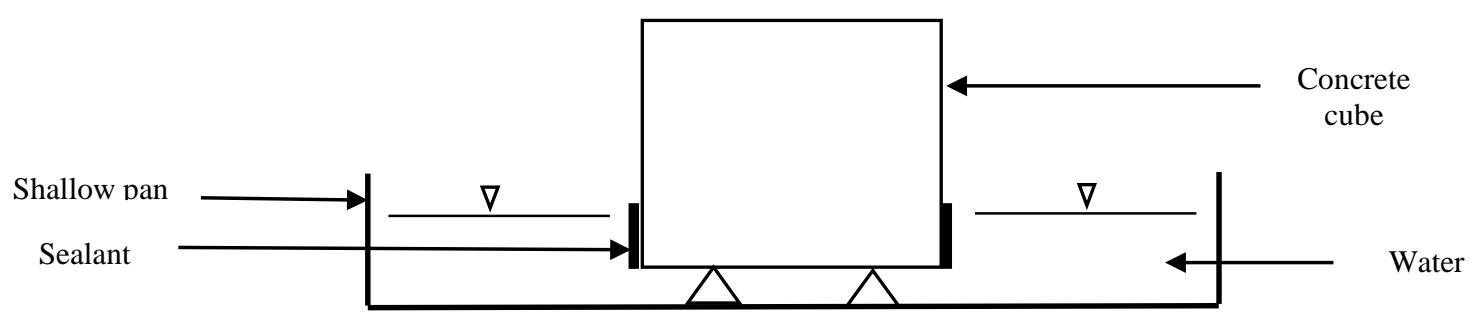

Fig - 2. Set up for the measurement of Coefficient of water absorption and Sorptivity of Concrete specimens (adaptation from [16]).

During the first 60 minutes, the quantity of water absorbed was calculated. This is done by measuring the increase in mass (gained over a period of 60 minutes) as a percentage of dry mass. Then, the coefficient of water absorption of concrete specimens containing EPO-FBA, after 28 and 90 days of moisture curing were determined using the formula used by [16].

$$
K_{a}=\left(\frac{Q}{A}\right)^{2} \times \frac{1}{t}
$$

where $K_{a}$ is the coefficient of water absorption $\left(\mathrm{m}^{2} / \mathrm{s}\right), Q$ is the quantity of water absorbed $\left(\mathrm{m}^{3}\right)$ by the oven dry specimen in time $(\mathrm{t})$, $t$ is 3600 seconds and $A$ is the surface area $\left(\mathrm{m}^{2}\right)$ of concrete specimen through which water penetrates.

\section{Sorptivity Test}

According to [15], sorptivity measures the rate of absorption of water by capillary suction of unsaturated concrete placed in contact with water, where no head of water exists, thus determining the rate of capillary-rise absorption by concrete specimens. This is a reflection of the capillary forces exerted by the pore structure causing fluids to be drawn into the body of the material $[16,18]$. A 


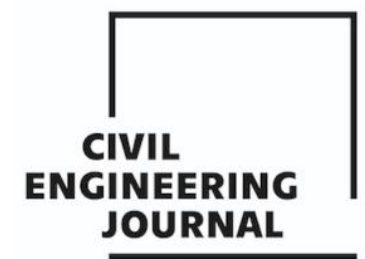

Article no. 38

THE CIVIL ENGINEERING JOURNAL 2-2021

method suggested by [21] was used to assess the sorptivity of concrete specimens with EPO-FBA as partial replacement of ordinary Portland cement. The test is similar to that of absorption test described above, but with little difference. The difference is that after the initial mass measurement of the cube samples was taken, subsequent mass measurement was taken at 4, 8, 10, 20, 30, 60, 90 and 120 minutes, and the gain in mass per unit area over the density of water was obtained. The gain in mass was then plotted against the square root of the elapsed time. The slope of the line of best fit of these points was taken as the sorptivity value. The formula (equation 2) suggested by [18] was then used to calculate the sorptivity of the specimens.

$$
i=\frac{s}{\sqrt{ } t}
$$

Where $i=$ the cumulative water absorption per unit area of the surface $\left(\mathrm{m}^{3} / \mathrm{m}^{2}\right)$; $\mathrm{S}$ is the sorptivity $\left(\mathrm{mm} / \mathrm{min}^{0.5}\right)$ and $\mathrm{t}$ is the elapsed time (s). The sorptivity of the concrete cube specimens containing EPO-FBA as partial replacement of ordinary Portland cement were determined after 28 and 90 days of water curing. The setup for the measurement of sorptivity values of the concrete cubes is shown in Figure 2 [16].

\section{Microstructural and Morphology Investigation}

Scanning electron microscopy (SEM) equipment (ASPEX 3020) with energy dispersive spectrometry capabilities was used for microstructural investigations. SEM investigations were carried out on broken sample of 28 days concrete specimens containing EPO-FBA as partial replacement of ordinary Portland cement, in order to examine their morphological structures.

\section{RESULTS}

\section{Physical and Chemical Properties of Materials}

The results of some physical properties of aggregates and that of the chemical properties of EPO-FBA are respectively presented in Tables 2 and 3.

Tab. 2: Some Physical Properties of Aggregates Used

\begin{tabular}{|l|c|c|}
\hline \multicolumn{1}{|c|}{ Properties } & Coarse Aggregates & Sand \\
\hline Bulk Density $\left(\mathrm{kg} / \mathrm{m}^{3}\right)$ & 1779.02 & 1387.79 \\
\hline Dry Density $\left(\mathrm{kg} / \mathrm{m}^{3}\right)$ & 1702.89 & 1501.60 \\
\hline Specific Gravity & 2.64 & 2.60 \\
\hline Moisture Content $(\%)$ & 3.87 & 6.07 \\
\hline Water Absorption Capacity $(\%)$ & 3.75 & 3.59 \\
\hline Coefficient of Curvature $\left(\mathrm{C}_{\mathrm{c}}\right)$ & 1.72 & 1.14 \\
\hline Coefficient of Uniformity $\left(\mathrm{C}_{\mathrm{u}}\right)$ & 4.75 & 6.70 \\
\hline Fineness Modulus & - & 2.62 \\
\hline
\end{tabular}

With coefficient of curvature or gradation $\left(\mathrm{C}_{\mathrm{c}}=\frac{D_{30} \times D_{30}}{D_{60} D_{10}}\right)$ and the coefficient of uniformity $\left(\mathrm{C}_{\mathrm{u}}=\right.$ $\left.\frac{D_{60}}{D_{10}}\right)$ calculated from the results of mechanical analysis for coarse aggregates to be 1.72 and 4.75 , and for the sand to be 1.14 and 6.70, as can be seen from Table 2, suggested well graded aggregate that will guaranty adequate compaction [20]. Also, the fineness modulus obtained for the sand is 2.62. This value satisfies [21] specifications for fine aggregates of between 2.3 and 3.1 for use for structural concrete. Though the combined total of $\mathrm{SiO}_{2}+\mathrm{Al}_{2} \mathrm{O}_{3}+\mathrm{Fe}_{2} \mathrm{O}_{3}$ in EPO-FBA (Table 3) is not up to the value that could allow classification into the categories of fly ash as per [21]. From Table 3, it can be seen that EPO-FBA has a higher loss on ignition (LOI) than that of cement and also greater than the limits of $5.0 \%$ set by [9]. The loss on ignition, a measure of the extent of carbonation and hydration of free lime and free magnesia is due to atmospheric exposure [15]. The higher value, according to [13], is actually advantageous as hydrated free lime is innocuous. The overall chemical composition of EPO-FBA as presented in Table 3, resembles bauxite (found in Ghana) and natural cement (found in UK) in the work of [24] which were found to have cementitious properties. 
Article no. 38

CIVIL

ENGINEERING

JOURNAL

THE CIVIL ENGINEERING JOURNAL 2-2021

Tab. 3: Chemical and Physical Properties of Empty Palm Oil Fruit Bunch Ash (EPO-FBA)

\begin{tabular}{|l|c|c|}
\hline \multicolumn{1}{|c|}{ Oxide } & EPO-FBA & OPC \\
\hline $\mathrm{CaO}(\%)$ & 19.01 & 64.37 \\
\hline $\mathrm{SiO}_{2}(\%)$ & 6.42 & 20.68 \\
\hline $\mathrm{Fe}_{2} \mathrm{O}_{3}(\%)$ & 6.64 & 3.62 \\
\hline $\left.\mathrm{MgO}^{2} \%\right)$ & 4.10 & 1.81 \\
\hline $\mathrm{Al}_{2} \mathrm{O}_{3}(\%)$ & 12.70 & 5.41 \\
\hline $\mathrm{SO}_{3}(\%)$ & 1.42 & 1.03 \\
\hline $\mathrm{Na}_{2} \mathrm{O}(\%)$ & 7.25 & 0.51 \\
\hline $\mathrm{K}_{2} \mathrm{O}(\%)$ & 1.86 & 0.47 \\
\hline $\mathrm{LOI}(\%)$ & 40.60 & 0.39 \\
\hline Specific Gravity & 2.55 & 3.12 \\
\hline
\end{tabular}

But the high alkali $\left(\mathrm{K}_{2} \mathrm{O}\right.$ and $\left.\mathrm{Na}_{2} \mathrm{O}\right)$ value $(9.11 \%)$ raises concerns about possible alkaliaggregate reaction if used in concrete without mitigating measures.

\section{Compressive Strength}

The compressive strength development of concrete samples containing EPO-FBA as partial replacement of cement is shown in Figure 3.

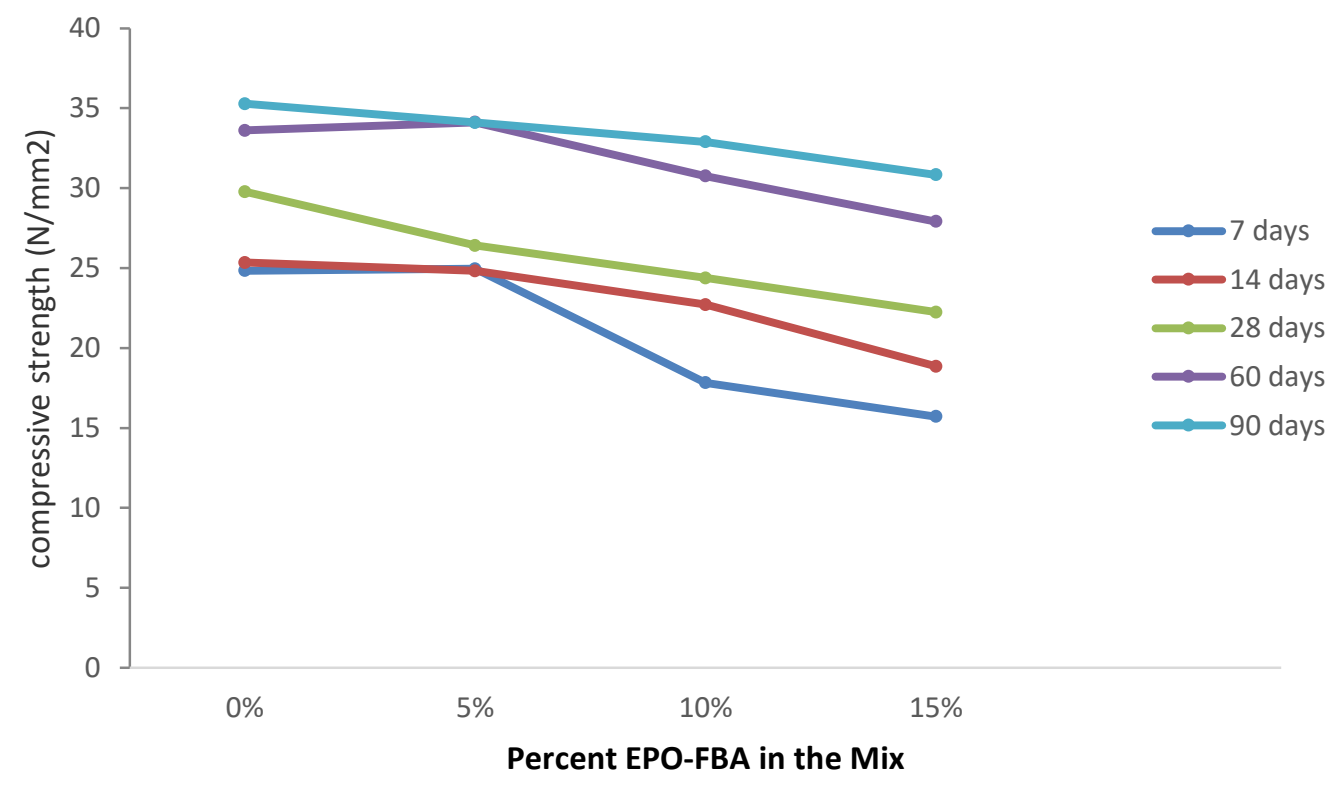

Fig. 3 - Compressive Strength Development of Concrete Samples with EPO-FBA

It can be observed that compressive strengths increased with increasing curing ages at all replacement values. This is a well-established trend. Continuous hydration produces the strengthformation C-S-H gel, and the more its quantity, the greater the strength that will be developed. However, the compressive strength of the samples decreased with increase in the content of EPOFBA in the mix. This can be observed in Table 4 through the perfomance criterion of strength activation index (SAI). However, this decrease, in relation to the control samples, was at a decreasing rate with curing ages. For example, in the concrete samples designated as $M_{15}$, the decreased were $68.69,74.39,74.68,81.85$, and $87.42 \%$ respectively at $7,14,28,60$ and 90 days of curing. This pattern was the same for concrete samples in other replacement values. According to [23], the strength activation index (SAI) can be used to assess the pozolanicity of any material. A compressive strength of the blended concrete sample at 7-day or/and 28 -day that is higher than $75 \%$ of the compressive strength of the control specimens suggests a material with pozzolanic 


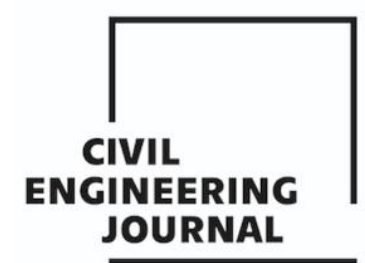

Article no. 38

THE CIVIL ENGINEERING JOURNAL 2-2021

characteristics. It can be observed from Table 4 that the specimens with 10\% EPO-FBA developed compressive strength that are higher than $75 \%$ of the control at both 7 and 28 days of curing. At higher curing ages of 60 and 90 days however, it can be observed that the SAI increased significantly to over $90 \%$ of the control.

Tab. 4: Compressive Strength Development of Concrete Samples with EPO-FBA

\begin{tabular}{|c|c|c|c|c|c|c|c|c|c|c|}
\hline \multirow[t]{4}{*}{ Mix } & \multicolumn{10}{|c|}{ Compressive Strength, CS $\left(\mathrm{N} / \mathrm{mm}^{2}\right)$ and Strength Activation Index, SAI } \\
\hline & \multicolumn{10}{|c|}{ Curing Age (days) } \\
\hline & \multicolumn{2}{|c|}{7} & \multicolumn{2}{|c|}{14} & \multicolumn{2}{|c|}{28} & \multicolumn{2}{|c|}{60} & \multicolumn{2}{|c|}{90} \\
\hline & CS & $\begin{array}{l}\text { SAI } \\
(\%)\end{array}$ & CS & $\begin{array}{l}\text { SAI } \\
(\%)\end{array}$ & CS & $\begin{array}{l}\text { SAI } \\
(\%)\end{array}$ & CS & $\begin{array}{l}\text { SAI } \\
(\%)\end{array}$ & CS & SAI \\
\hline Mo & 24.84 & 100.00 & 25.34 & 100.00 & 29.78 & 100.00 & 33.61 & 100.00 & 35.28 & 100.00 \\
\hline $\mathrm{M}_{5}$ & 24.96 & 100.48 & 24.82 & 97.95 & 26.42 & 88.72 & 34.12 & 101.52 & 34.11 & 96.68 \\
\hline $\mathrm{M}_{10}$ & 19.82 & 79.79 & 22.71 & 89.62 & 24.38 & 81.87 & 30.75 & 91.49 & 32.90 & 93.25 \\
\hline$M_{15}$ & 15.82 & 63.69 & 18.85 & 74.39 & 22.24 & 74.68 & 27.51 & 81.85 & 30.84 & 87.42 \\
\hline
\end{tabular}

It is thus obvious that on the basis of the data presented in Table 4, that concrete samples with up to $10 \%$ EPO-FBA content meet the performance index criterion for pozzolanicity.

\section{Durability}

The durability properties of concrete samples containing EPO-FBA were assessed through water absorption and sorptivity tests; and the results are presented in Figures 4 . Though both measured different things - water absorption measuring volume of pore space in the concrete and sorptivity measuring the rate of capillary-rise absorption - they were in agreement in relation to the durability properties of concrete specimens containing EPO-FBA. From figure 4(a), it can be observed that the water absorption of concrete specimens containing EPO-FBA was lower at 90 days than at 28 days. This is suggestive of reduction in the volume of pore space in the concrete specimens at longer curing ages. Sorptivity reflects the capillary porosity on which the permeability of hardened cement paste is dependent [15]. Permeability on the other hand, is a reflection of the interconnectivity of pores in the paste. From Figure 4(b), it can be observed that the 90 days sorptivity of samples were lower than that of 28 days samples. This means 90 days samples are less porous or less permeable than 28 days samples.

The results of durability characteristics of specimens with EPO-FBA presented in Figure 4, can be explained in relation to the pore structure of the hydrated paste phase. With the progress of hydration, the hydration products (the C-S-H gel) fill the originally water-filled void [15]. This not only reduces the volume of pore space in the samples, but also results in discontinuity of pores. This results in reduced permeability with time, observed for 90 days specimens, as more hydration products continue to fill the available pores. The results of the durability test also agree with the pattern of strength development of concrete samples with EPO-FBA, in which strength development improved with curing age, as discussed in section 3.2. 


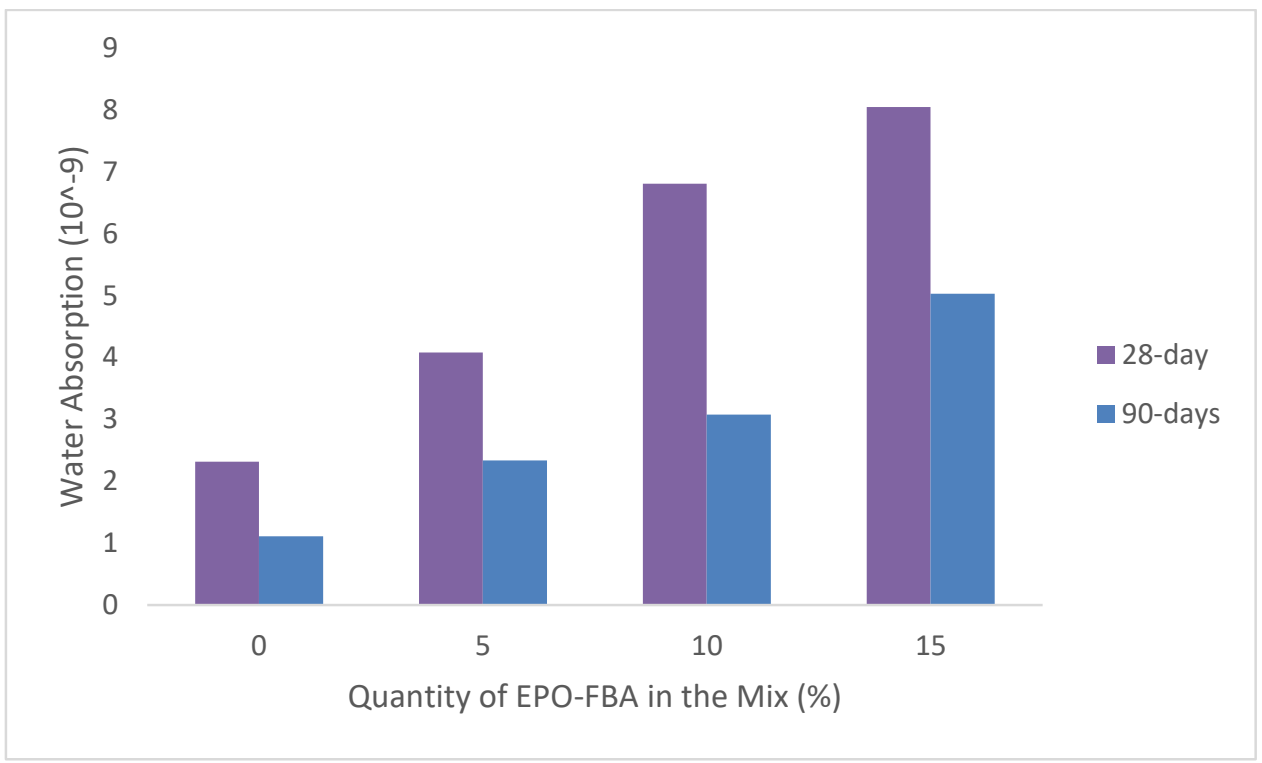

a) Water Absorption of Concrete Samples with EPO-FBA

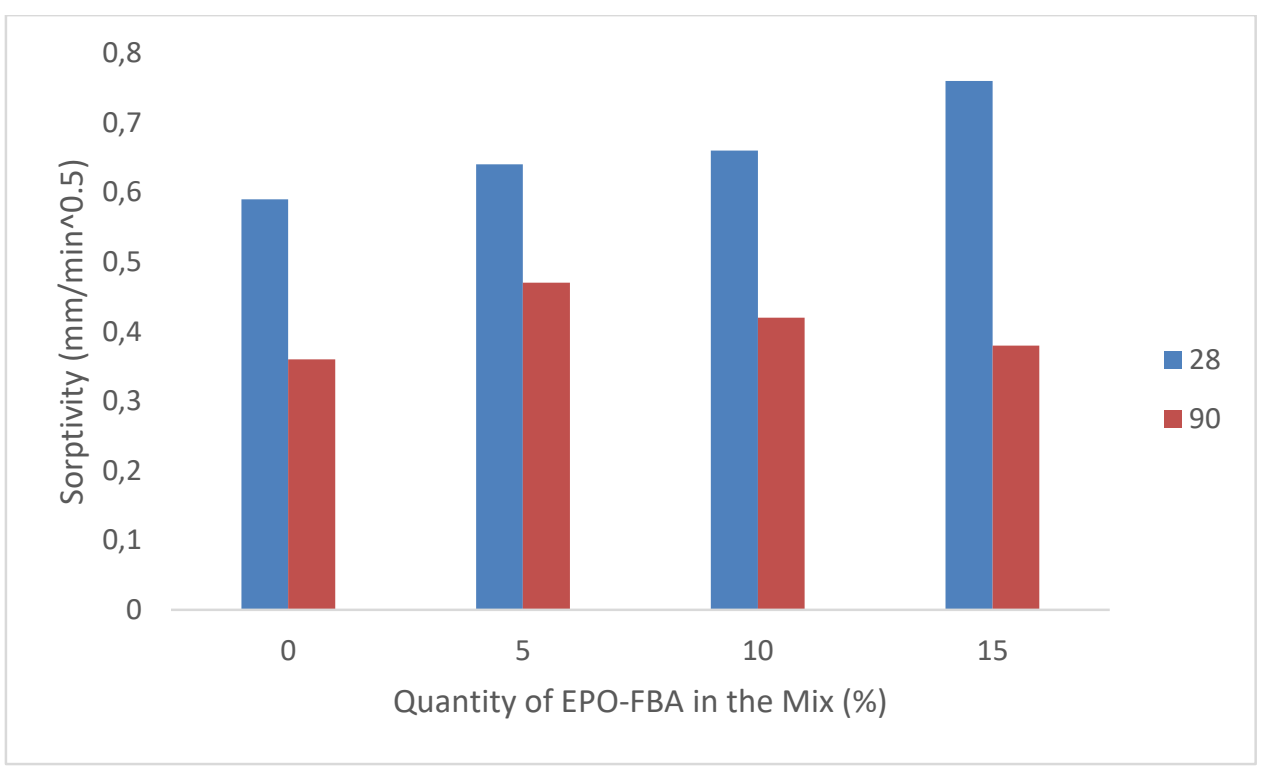

b) Sorptivity of Concrete Samples with EPO-FBA

Fig. - 4 Durability Properties of Concrete Samples with EPO-FBA

According to [15], there is a relationship between the relative volume of hydrated products gel in the space available to it (permeability) and strength. As hydration continues unhindered, hydration products are formed with the double effect of increased strength and reduced permeability in the concrete samples, as witnessed in this work.

\section{Microstructure}

The SEM micrographs of concrete samples with EPO-FBA at replacement levels of $0 \%, 5 \%$, $10 \%$ and $15 \%$ cured for 28 days are shown in Figures 5 and 6, for a glimpse into the structure of the hydrated paste samples. In relation to the control, the microstructure appears to be progressively less dense or of increased porosity due to reduced formation of C-S-H gel. 


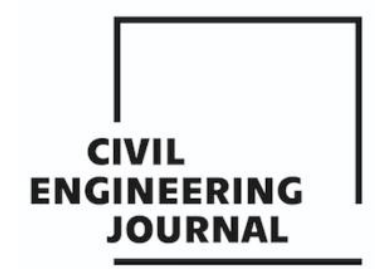

Article no. 38

THE CIVIL ENGINEERING JOURNAL 2-2021

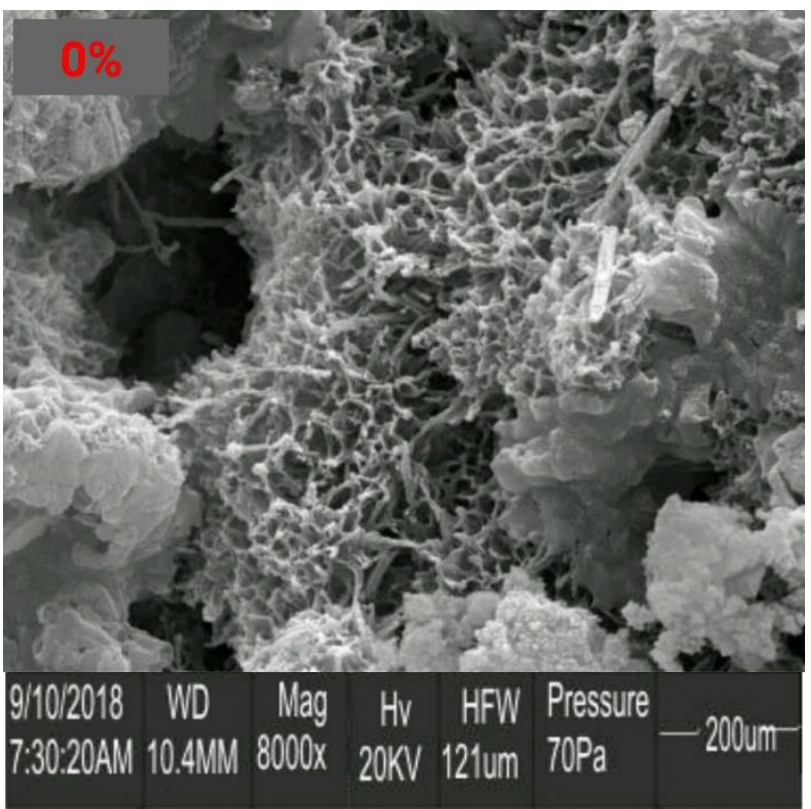

Fig. 5 - SEM Images for Concrete samples with EPO-FBA (Control)

It appears that higher EPO-FBA replacement percentage has relatively lighter structure. The SEM images of the control samples show a well-developed aggregate-cement paste interface and the hydration product C-S-H (Calcium Silicate Hydrate) can be seen as honeycombs structure with some surrounding few pores but no crack. On the other hand, the $5 \%$ replacement level with EPOFBA shared similar characteristics with that of the control sample. The strength forming product of hydration C-S-H can be seen surrounding the whole aggregate structure with many pores compared to that of $0 \%$ replacement. The SEM micrograph for $10 \%$ and $15 \%$ of EPO-FBA show pores that are large and the structure becomes relatively porous, thus less densely-packed. This can be connected to the fact that there is reduction in the quantity of strength forming hydration product $\mathrm{C}-\mathrm{S}-\mathrm{H}$ as the quantity of EPO-FBA increases. The EDX spectrum of the concrete samples are shown in figure 7.
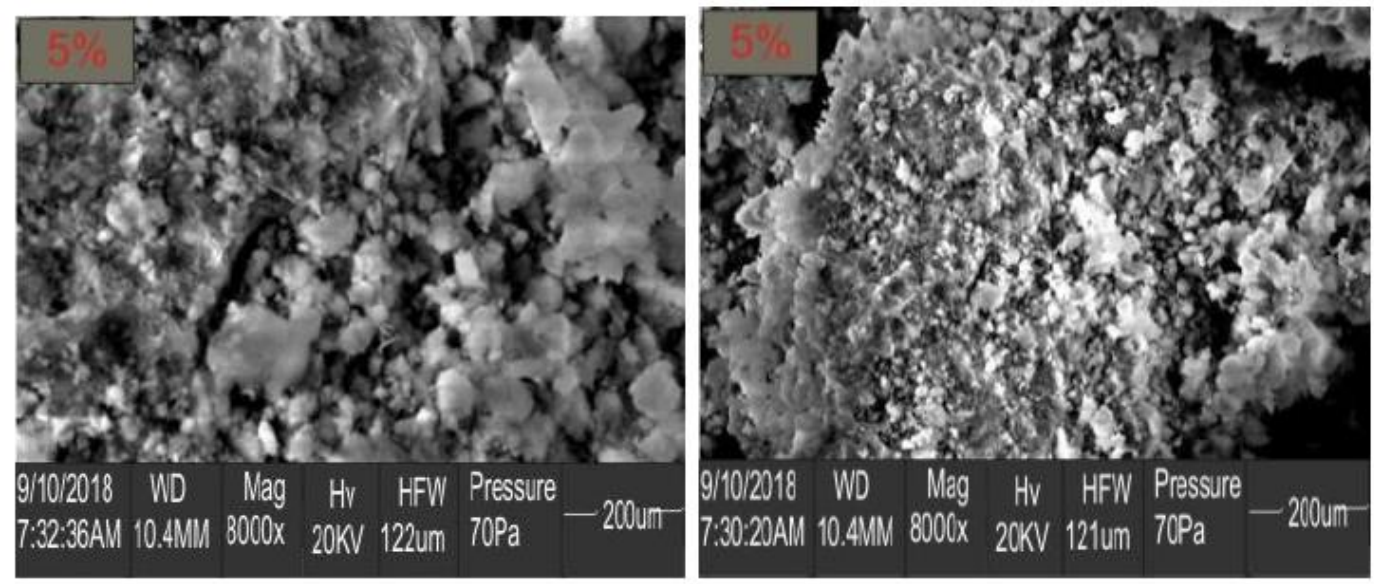

Fig. 6 - SEM Images for Concrete Samples with EPO-FBA (5, 10, \& 15\%) 

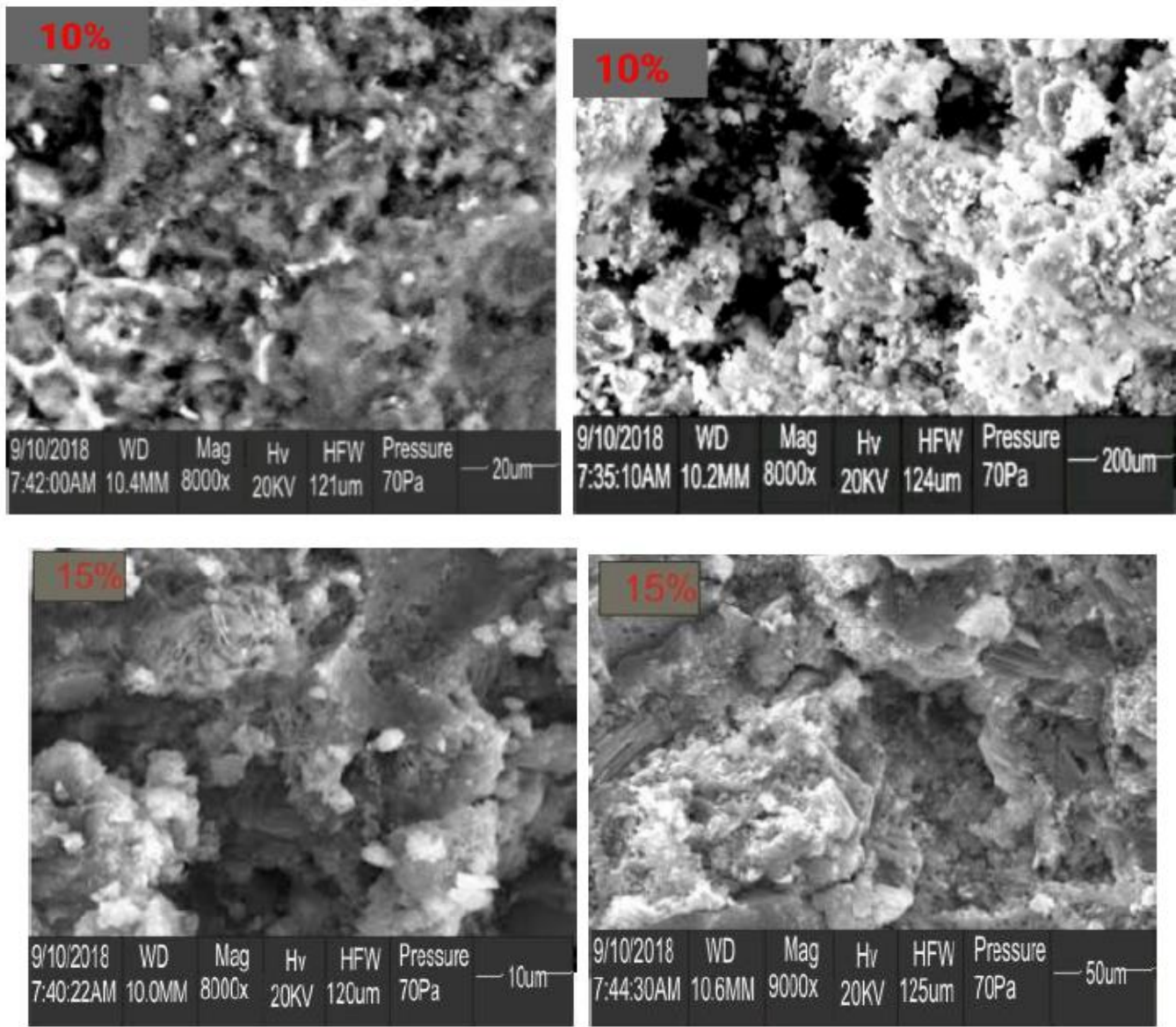

Fig. 6 - SEM Images for Concrete Samples with EPO-FBA (5, 10, \& 15\%)
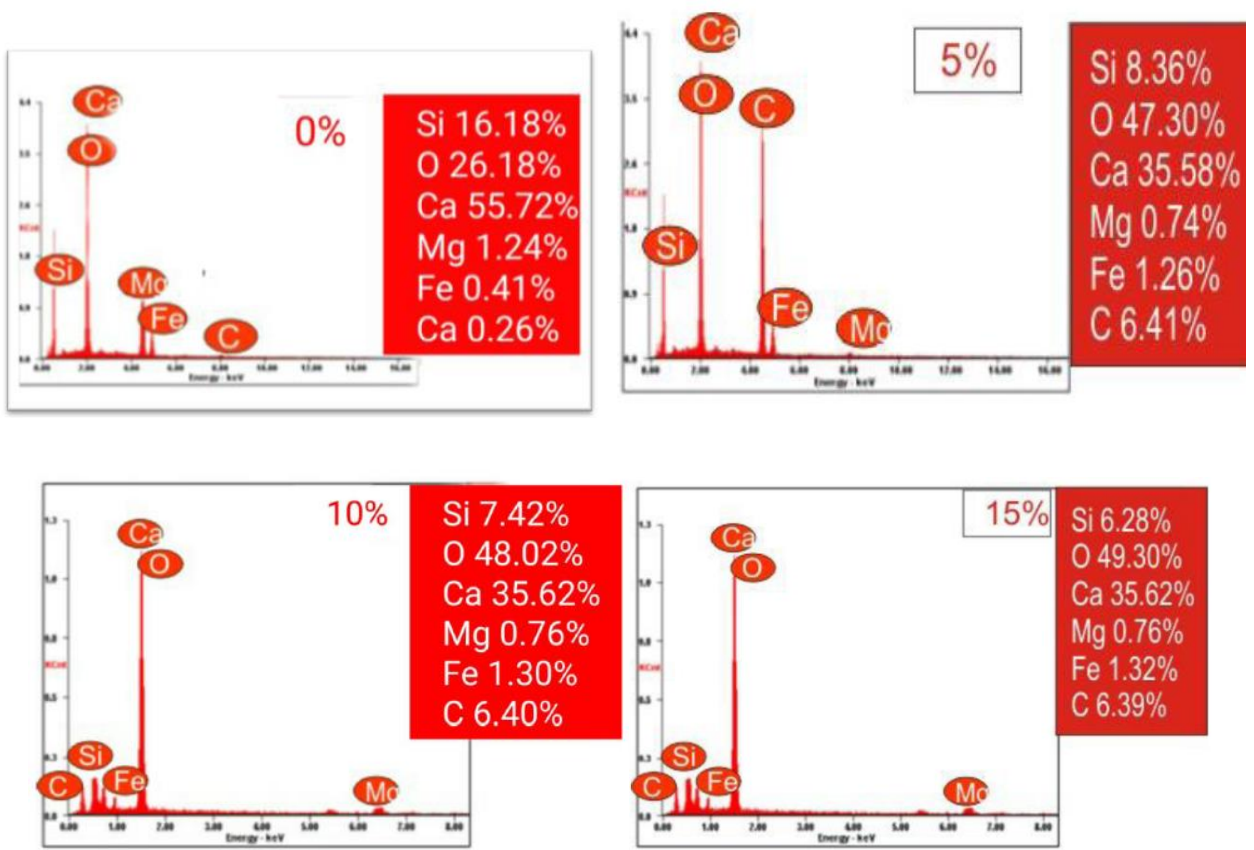

Fig 7 - The EDX Spectrum of Samples with EPO-FBA (0, 5, 10 \& 15\%) 


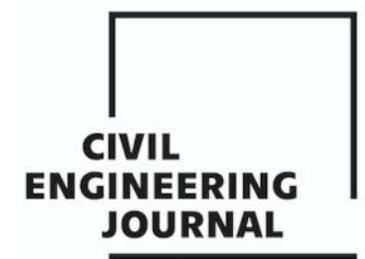

Article no. 38

THE CIVIL ENGINEERING JOURNAL 2-2021

It can be seen that the count of Silicon and Calcium which are the main element responsible for the strength forming and bonding of concrete structure declines with increasing EPO-FBA (Table $5)$.

Tab. 5 - The C/S Ratio of Mixes with EPO-FBA

\begin{tabular}{|c|c|c|c|}
\hline $\begin{array}{c}\text { Mix } \\
\text { Designation }\end{array}$ & $\mathrm{Ca}(\mathrm{C})$ & $\mathrm{Si}(\mathrm{S})$ & $\frac{C}{S}$ \\
\hline $\mathrm{M}_{0}$ & 55.72 & 16.18 & 3.44 \\
\hline $\mathrm{M}_{5}$ & 35.58 & 8.36 & 4.26 \\
\hline $\mathrm{M}_{10}$ & 35.62 & 7.42 & 4.80 \\
\hline $\mathrm{M}_{15}$ & 35.62 & 6.28 & 5.67 \\
\hline
\end{tabular}

This contributes to the reason why there is decrease in the compressive strength of concrete with increasing EPO-FBA. The ratio of silicon and carbon however increased with increase in the quantity of EPO-FBA in the mix. According to [26], increasing ratio means increasing pozzolanic activities. But this would not be felt until later ages, as can be seen from the result of the compressive strength and sorptivity. This is characteristic of SCM, with well-known latent pozzolanic properties.

\section{CONCLUSIONS AND RECOMMENDATION}

From the analysis of the results of this investigation, the following conclusions can be made:

1. Partly replacing the cement fraction of concrete mix with empty palm oil fruit bunch ash (EPOFBA) led to reduction in compressive strength. However, replacement at $10 \%$ of the cement by weight will develop strength comparable to the control.

2. The compressive strengths of concrete samples with EPO-FBA continued to improve with curing ages at all the replacement level considered in this investigation.

3. Concrete specimens with EPO-FBA developed improved durability characteristics with age.

4. The microstructure of 28-day concrete specimens with EPO-FBA showed porous microstructure, but with latent pozzolanic activities.

It is obvious from the analysis of the results of this investigation that a relationship exists between the compressive strength, durability properties and morphological structures of the concrete samples containing EPO-FBA as partial replacement of cement. Although this investigation can be considered as preliminary, that the concrete samples have heterogeneous microstructure, with the pores (sizes and distribution) playing a significant role in the quality of the concrete samples, is not in doubt. For innovative application of EPO-FBA in structural concrete, more research works aimed at finding ways to reduce the pores, not only at latter ages, but at earlier ages, is necessary. Research works in this area are thus recommended.

\section{ACKNOWLDGEMENT}

Sincere appreciations to Ms. Blessing Adigo for reading through this manuscript.

\section{REFERENCES}

[1] Scrivener K. R., 2018. The Microstructure of Concrete. Materials Science of Concrete, 18 pp. Retrieved from www.comisiru.uct.ac.za/../The Microstructure of Concrete.pdf .

[2] Mehta P. K., Monteiro P. J. M., 2014. Concrete: Microstructure Properties and Materials. McGraw Hill Education, New York, USA, 239 pp.

[3] Boccaccini A. R. 2005. Ceramics. Biomaterials, Artificial Organs and Tissue Engineering. Woodhead Publishing Series in Biomaterials. Retrieved from https//doi.org/10.1533/9781845690861.1.26.

[4] Fapohunda C. A., Shittu A. O., 2017. Some Later Ages Structural Characteristics of Concrete Containing Empty Palm Oil Fruit Bunch Ash (EPO-FBA) as Partial Replacement of Ordinary Portland Cement. FUOYE Journal of Engineering and Technology, vol. 2, nos. 1: 42-46. 


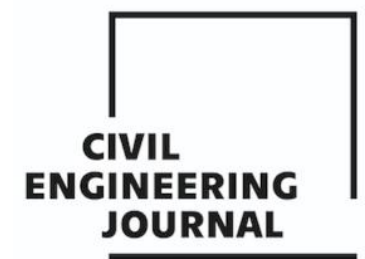

Article no. 38

THE CIVIL ENGINEERING JOURNAL 2-2021

[5] Bamforth P., Chisholm D., Gibbs J., Harrison T. 2008. Properties of Concrete for use in Eurocode 2 How to optimise the engineering properties of concrete in design to Eurocode 2. A Cement and Concrete Industry Publication. Retrieved from www.concretecentre.com.

[6] Fapohunda, C. A. and Oluwasegunota, O. B. (2019). Evaluation of Structural Performance of Concrete With OPC Fraction Partly Replaced By Empty Palm Oil Bunch Ash (Epo-Fba). FUW Trends in Science \& Technology Journal, vol. 4, Nos. 1: $202-208$

[7] Coelho, V. A., Guimaraes, C. C., Doutto, G. G. And Pedra, P. M. (2019). Evaluation Of Mortar Properties Obtained Through Partial Substitution Of Portland Cement By Ashes Of Oil Palm Empty Fruit Bunch. Cerâmica vol. 65, 375. https://doi.org/10.1590/0366-69132019653752575

[8] NIS 444-1, 2014. Cement - Part I: Composition and Conformity Criteria for Common Cements. Standard Organization of Nigeria, Abuja, Nigeria.

[9] BS EN 197-1, 2000. Cement, Composition, Specification and Conformity Criteria for Common Cements. British Standard Institution, London, U.K.

[10] BS EN 12620:2002, 2008. Specification for Aggregates from Natural Sources for Concrete. British Standard Institution, London, U.K.

[11] BS 8110, 1997. Structural Use of Concrete - Code of Practice for Design and Construction. British Standard Institution, London, U.K.

[12] Oyekan G. L., Kamiyo, O. M., 2011. A study on the engineering Properties of Sandcrete Blocks produced with Rice Husk Ash Blended Cement. Journal of Engineering and Technology Research, vol. 3, nos. 3: 88-98.

[13] ASTM C 1602, 2012. Standard Specification for Mixing Water Used in the production of Hydraulic Cement Concrete. ASTM International, Philadelphia, USA.

[14] BS EN 12390-3, 2009. Testing Hardened Concrete: Compressive Strength of Test Specimens. British Standard Institution, London, U.K.

[15] Neville A. M., 2011. Properties of Concrete. Pearson Educational Publishers, London, U. K. 779 pp.

[16] Ganesan K., Rajagopal K., Thangavel K., 2008. Rice husk ash blended cement: assessment of optimal level of replacement for strength and permeability properties of concrete. Construction and Building Materials, vol. 22, nos. 8:1675-1683.

[17] Giannotti-da-Silva F., Liborio J. B. L., Helene P. 2008. Improvement of physical and chemical properties of concrete with Brazilian silica rice husk (SRH). Revista Ingeniería de Construcción, vol. 23, nos. 1:18-25.

[18] Hall C., 1989. Water sorptivity of mortars and concretes: A review. Magazine of Concrete Research, vol. 41, nos. 14: 51-61.

[19] ASTM C 1585, 2004. Standard Test Method for Measurement of Rate of Absorption of Water by Hydraulic Cement Concrete. ASTM International, Philadelphia, USA.

[20] Stanish K. D., Hooton R. D., Thomas M. D. A., 1997. Testing the chloride penetration resistance of concrete: a literature review, FHWA contract DTFH61. Department of Civil Engineering, University of Toronto, Toronto.

[21] Terzaghi K., Peck R. B., Mesri G., 1996. Soil Mechanics in Engineering Practice. John Wiley, New York, USA. $549 \mathrm{pp}$.

[22] ASTM C 33 (1997). Concrete and Aggregates - ASTM Standards, Concrete and Aggregates. ASTM International, Philadelphia, USA.

[23] ASTM C 618 (2005) Standard Specification for Coal Fly Ash and Raw or Calcined Natural Pozzolan for Use in Concrete. ASTM International, Philadelphia, USA.

[24] Day R. L., 1990. Pozzolans for Use in Low-Cost Housing - A State of the Art Report for the International Development Research Centre, Ottawa. Department of Civil Engineering, University of Calgary, Canada.

[25] Malhotra V. M., Mehta P. K., 1996. Pozzolanic and Cementitious Materials - Advances in Concrete Technology. Volume 1. Edited by V.M. Malhotra. Gordon and Breach Publishers, Ottawa, Canada.

[26] Nazari A., Rafieipour M. H., Riahi S., 2011. The Effects of CuO Nanoparticles on Properties of Self Compacting Concrete with GGBFS as Binder. Materials Research, vol. 14, nos. 3: 307-316. 